\title{
estudios
}




\section{Ruinas modernas y arte contemporáneo: el caso de El Helicoide de la Roca Tarpeya}

Modern Ruins and Contemporary Art: the Case of El Helicoide de la Roca Tarpeya

Ruínas modernas e arte contemporânea: o caso de El Helicoide da Roca Tarpeya

\section{Lisa Blackmore}

UNIVERSITY OF ESSEX, REINO UNIDO

Profesora de Historia del Arte y Estudios Interdisciplinarios en la

Universidad de Essex, y PhD por Birkbeck College de The University

of London. Su libro Spectacular Modernity: Dictatorship, Space

and Visuality in Venezuela, 1948-1958 se publicó con University

of Pittsburgh Press en 2017 y es co-editora con Celeste Olalquiaga

de Downward Spiral: El Helicoide's Descent from Mall to Prison

(Urban Research/Terreform, 2018). Sus artículos arbitrados incluyen:

"Collective Memory and Research-led Filmmaking: Spatial

Legacies of Dictatorship in the Dominican Republic" (Popular

Communication, octubre 2017); "El Helicoide and La Torre de

David as Phantom Pavilions: Rethinking Spectacles of Progress

in Venezuela" (Bulletin of Latin American Research, julio 2016), $y$

"Capture life: the 'document-monument' in Recent Commemorations

of Hugo Chávez" (Fournal of Latin American Cultural Studies

23.3, 2014). Correo electrónico: lisa.blackmore@essex.ac.uk

Artículo de reflexión

Documento accesible en línea desde la siguiente dirección: http://revistas.javeriana.edu.co 


\section{Resumen}

Atendiendo a recientes

discusiones sobre las ruinas modernas, este artículo propone que el arte contemporáneo ofrece vías para mirar y relatar estos monumentos truncos sin neutralizarlos como patrimonios nostálgicos ni reducirlos a meras imágenes desprovistas de sus heterogéneas historias.

Tomando como caso de estudio El Helicoide - un audaz centro comercial convertido en sede policial - analizo tres instalaciones que capturan el potencial productivo de las ruinas para mostrar el "andamiaje ideológico" (Boym) de la arquitectura y ensayar nuevas formas monumentales (Rancière).

Palabras clave: arquitectura moderna; ruina moderna; monumento; arte contemporáneo; Venezuela

\section{Abstract}

In light of recent discussions on modern ruins, this article suggests that contemporary art offers ways of looking at and describing these truncated monuments without neutralizing them as nostalgic heritage or reducing them to simple images devoid of their heterogeneous histories. Taking 'El Helicoide', an audacious shopping mall turned into a police station, as a case study, we analyzed three facilities that capture the productive potential of ruins as to show the "ideological scaffold" of architecture (Boym) and test new monumental forms (Rancière).

Keywords: modern architecture; modern ruins; monument; contemporary art; Venezuela

\section{Resumo}

Atendendo a recentes discussões sobre as ruínas modernas, este artigo propõe que a arte contemporânea oferece vias para observar e relatar tais monumentos truncados sem neutralizá-los como patrimônios nostálgicos nem reduzi-los a meras imagens desprovidas das suas histórias heterogéneas. Tomando como caso de estudo El Helicoide - um audaz shopping convertido em sede policial- analiso três instalações que capturam o potencial produtivo das ruínas para mostrar o "arcabouço ideológico" (Boym) da arquitetura e ensaiar novas formas monumentais (Rancière).

Palavras-chave: arquitetura moderna; ruína moderna; monumento; arte contemporânea; Venezuela

RECIBIDO: 16 DE MARZO DE 2016. ACEPTADO: 11 DE MAYO DE 2016. DISPONIBLE EN LÍNEA: 29 DE DICIEMBRE DE 2017

Cómo citar este artículo:

Blackmore, Lisa. "Ruinas modernas y arte contemporáneo: el caso de El Helicoide de la Roca Tarpeya". Cuadernos de Literatura 21.42 (2017): 255-277. https://doi.org/10.11144/Javeriana.cl21-42.rmac 
EN LOS ÚLTIMOS años han emergido conjuntamente un auge de interés en la revisión del legado del modernismo en la arquitectura y un giro hacia la figura de la ruina moderna en la historia cultural. Este primer impulso puede rastrearse hasta la utilización de tecnologías de exposición implementadas para evaluar la modernidad arquitectónica como legado complejo o patrimonio resplandeciente, tal como propusieron respectivamente las muestras Absorbing Modernity (Biennale di Venecia, 2014) y Latin America in Construction: Architecture 1955-1980 (MoMA, 2015). ${ }^{1}$ Por su parte, en el campo de la crítica y la historia cultural, el incremento de bibliografía sobre las ruinas modernas ha dado como frutos compilaciones como Ruins of Modernity (Hell y Schönle, 2010) y Telling Ruins in Latin America (Lazarra y Unruh, 2009), cuya metodología común ausculta los heterogéneos relatos inscritos en los remanentes de grandes construcciones ideadas como augurios de progreso, pero luego truncadas, alteradas o hasta abandonadas.

Estas dos vertientes coinciden en una pregunta fundamental: ¿cómo podemos dar cuenta de la monumentalidad moderna y/o de sus ruinas desde la contemporaneidad? Sin embargo, sus procederes tienden a enfatizar aspectos diferentes para generar sus respuestas. Mientras el enfoque expositivo-patrimonial suele volver a mirar los planes originales de monumentos modernos, la crítica cultural tiende a abordar las ruinas como "palimpsestos" para verbalizar sus relatos como testimonios de la historia reciente (Huyssen, Present Pasts). Aunque este sea un juicio formulado a grosso modo, la distinción ayuda a señalar un desafío que persiste a la hora de evaluar el legado moderno y sus ruinas, el cual es: ¿cómo abordar simultáneamente sus características visuales y testimoniales para pensarlos de modo crítico?

Tomemos como ejemplo Latin America in Construction, para mostrar un desafío específico que emerge en la aproximación expositiva al legado moderno. La muestra ejemplificó una premisa conmemorativa que, al enfatizar casi exclusivamente la exhibición de planos, maquetas, dibujos, fotografías, todos artefactos que restituían la visión original de estos proyectos, renuncia

1 No era la primera vez que el MoMA realizaba una exposición de arquitectura moderna latinoamericana, y esta muestra tuvo antecedentes en Brazil Builds (1943) y Latin American Architecture since 1945 (1955), como lo nota Patricio del Real en su publicación del año 2007. Mientras que la muestra del Moma fue de corte más bien conmemorativo, la Biennale - bajo la curaduría general de Rem Koolhaus- potenció mucho más la revisión crítica de la modernidad arquitectónica en relación al contexto sociopolítico, como lo ejemplificaron los pabellones de Chile y República Dominicana, entre otros. 
a la oportunidad de evaluar críticamente los trasfondos políticos e ideológicos de la arquitectura y sus contextos actuales. ${ }^{2}$ Lejos de ser anómala, esta omisión de las posvidas arquitectónicas más bien caracteriza un mecanismo apto para producir el valor patrimonial que enfatiza representaciones "virtuales" sobre representaciones "actuales" (Kirshenblatt-Gimblett 369$).{ }^{3}$ El problema de este enfoque, no solo porque puede fomentar nostalgia por las promesas optimistas sino porque tiende a minimizar los procesos sociopolíticos, económicos y afectivos que transforman un espacio en un "lugar-mundo" (place-world), aplana los matices requeridos para pensar las mutaciones de monumentales arquitecturas en ruinas modernas (Casey 228).

En este sentido, es significativo que varios textos críticos recientes inviten a entender estos desencuentros que se dan entre los espacios conjeturados y sus usos posteriores, como los cimientos de las ruinas modernas y las claves que dirigen a sus potenciales testimoniales. En América Latina, Beatriz Jaguaribe (1999), Rubén Gallo (2009) y Jon Beasley-Murray (2015) han hurgado en las fisuras literales y las grietas metafóricas de las ruinas modernas para iluminar desplazamientos sociales, políticos y económicos más amplios. Para Jaguaribe, la decadencia de edificios modernistas en Brasil evidencia la crisis de un paradigma de desarrollo en el que la construcción monumental equivalía a la realización nacional. Gallo ve en el cambio del conjunto habitacional Tlatelolco, de proyecto residencial a escenario de la masacre de 1968, "el símbolo más oscuro de los fracasos distópicos de México" (114). Y, en la fragmentariedad de las ruinas del Hospital Ochagavía, baluarte de Allende, abandonado bajo Pinochet, Beasley-Murray detecta una resistencia a las pretensiones de univocalidad de los discursos hegemónicos. Esta interpelación de las ruinas como testigos de sus complejos entornos confronta los desafíos sugeridos por el doble sentido del título Telling Ruins del volumen comentado arriba. Al presentar la ruina como un rastro elocuente (telling), supone que su excavación la hará ir relatando (telling) sus historias.

Evidentemente, hay mucho interés en revisar la monumentalidad y en pensar sus ruinas, pero persisten desafíos a la hora de poder atender simultáneamente su carga iconográfica y su contenido ideológico. En otras palabras, ¿cómo podemos abordar las relaciones de espacio-lugar, imagen-relato para

2 Esta tendencia tuvo una sola excepción: un video de entrevistas con residentes del proyecto Previ en Lima, Perú, que sí abordó el interrogante crucial de cómo estos proyectos habían sido moldeados por los contactos con sus usuarios y los contextos en los cuales se emplazaron

Todas las traducciones en el artículo corresponden a su autora. 
pensar tanto la monumentalidad moderna como sus ruinas? ${ }^{4}$ Respecto a este desafío, el enfoque de Svetlana Boym, evidente en su texto de 2009, ofrece claves útiles porque aboga por un acercamiento integral capaz de revisar cómo la monumentalidad y sus ruinas participan de regímenes ideológicos-visuales. $\mathrm{Al}$ partir de un concepto de arquitectura monumental como "andamiaje que contiene una visión del mundo y un esqueleto para sueños futuristas", enfoca los fundamentos ideológicos que hacen de la ruina moderna un residuo de ese régimen ("Ruins of the Avant-garde" 64).

Quisiera proponer que el arte contemporáneo fragua estrategias de representación de las ruinas modernas que nos invitan a mirarlas de un modo igualmente crítico para cuestionar sus premisas monumentales y relatar sus complejas y a veces oscuras historias. No obstante, antes de cualquier análisis específico, cabe señalar que el mero registro visual de las ruinas modernas no garantiza una revisión productiva de su condición visual, carga ideológica o potencial testimonial. $\mathrm{Al}$ contrario, esta tarea enfrenta de antemano el reto propuesto por la preexistencia de una dilatada tradición cultural de embellecer las ruinas, que se remonta al Romanticismo; pasa por textos modernos como Pleasure of Ruins (1953) de Rose Macaulay, y llega hasta nuestro contexto contemporáneo, en el que las fotografías digitales de edificios abandonados se han convertido en lugares comunes, sintomáticos de un banalizado ruin lust (deseo de ruina), para utilizar la frase de Brian Dillon (lo que se verifica en el texto del mismo nombre del 2014). Es en vista de este bagaje cultural que algunos autores anticipan la estetización de la ruina moderna como un hecho "inevitable" (Hell y Schönle 1) y alertan el riesgo de reducirla a un patrimonio nostálgico o una imagen romantizada.

Una aproximación estética-crítica a las ruinas modernas, basada en estas advertencias, precisa el engranaje de mirar, representar y relatar: un proceder reflexivo que va "apuntando imperfecciones, grietas, y excentricidades que interrumpen esquemas arquitectónicos y teleológicos" de los contextos en los que las construcciones monumentales se fueron arruinando (Boym, "Ruins of the Avant-garde" 80). El modo más directo de considerar esta aproximación consiste en analizar un conjunto de obras de arte relacionadas con una ruina específica, por lo que tomaré como caso de estudio El Helicoide de la Roca Tarpeya (1955): un edificio modernista ubicado en Caracas, Venezuela, y diseñado inicialmente como un lujoso centro comercial, pero convertido más adelante en sede policial. 
Como lugar sujeto a los vaivenes económicos, políticos y sociales que han moldeado la realidad venezolana en los últimos sesenta años, El Helicoide es una ruina moderna por excelencia (figura 1). ${ }^{5}$ El edificio comenzó como una inversión privada durante el boom petrolero de la dictadura militar que tuvo lugar de 1948 a 1958, pero su construcción paró en la transición a la democracia emprendida a partir de 1958. Luego de años en abandono, el Estado comisionó una serie de infructuosos proyectos para la reinvención de El Helicoide, antes de utilizarlo como refugio para damnificados, pues más adelante, en la década de 1980, habría de disponerlo como sede principal de la policía de inteligencia. A pesar de la adición de una academia para el liderazgo, de una reforma policial en 2010 y una reciente orden presidencial de estudiar su conversión en un centro cultural, las funciones policiales y carcelarias de la construcción han resultado ser las únicas duraderas.

Con su diseño audaz, carga simbólica y tumultuosa historia, El Helicoide es una presencia fascinante en el paisaje urbano y el imaginario colectivo. Esto, aunado a los continuos intentos por darle un significado cohesivo, ayuda a explicar por qué tantos artistas venezolanos lo han representado en diferentes medios,

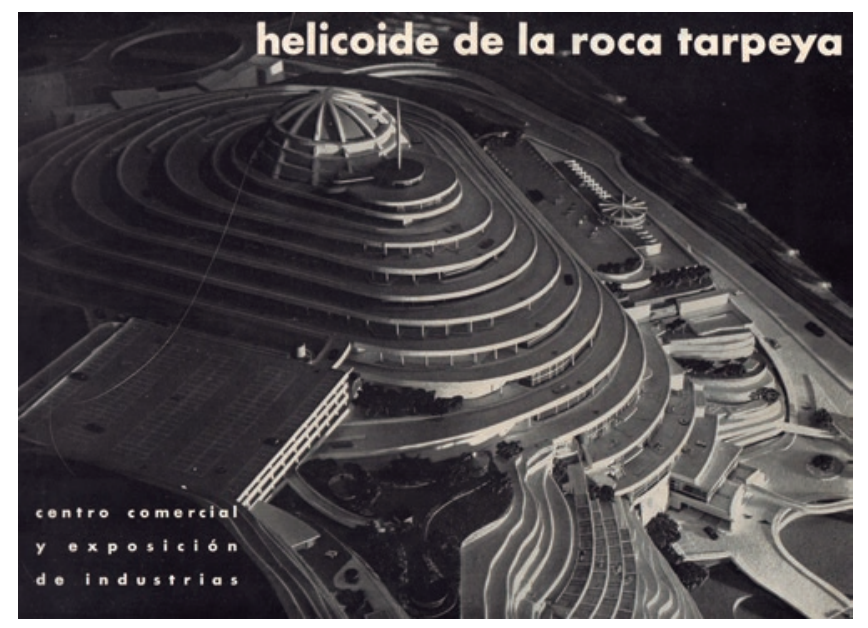

Figura 1. Maqueta de El Helicoide, fotografía anónima. Archivo de Fotografía Urbana/ PROYECTO HELICOIDE (s/f).

5 Sobre la historia y diseño del edficio, véanse los textos de Bornhorst del año 2007; de Olalquiaga, del 2014, y Villota, del 2014. El Helicoide fue diseñado por tres arquitectos: Jorge Romero Gutiérrez, Pedro Neuberger y Dirk Bornhorst. 
desde el video y la fotografía, hasta el dibujo y el collage. En la discusión que sigue estudiaré tres obras producidas entre 1998 y 2014, para identificar cómo superan la representación nostálgica o romantizada de El Helicoide, y cómo abordan la ruina para indagar en realidades más amplias y así repensar la monumentalidad.
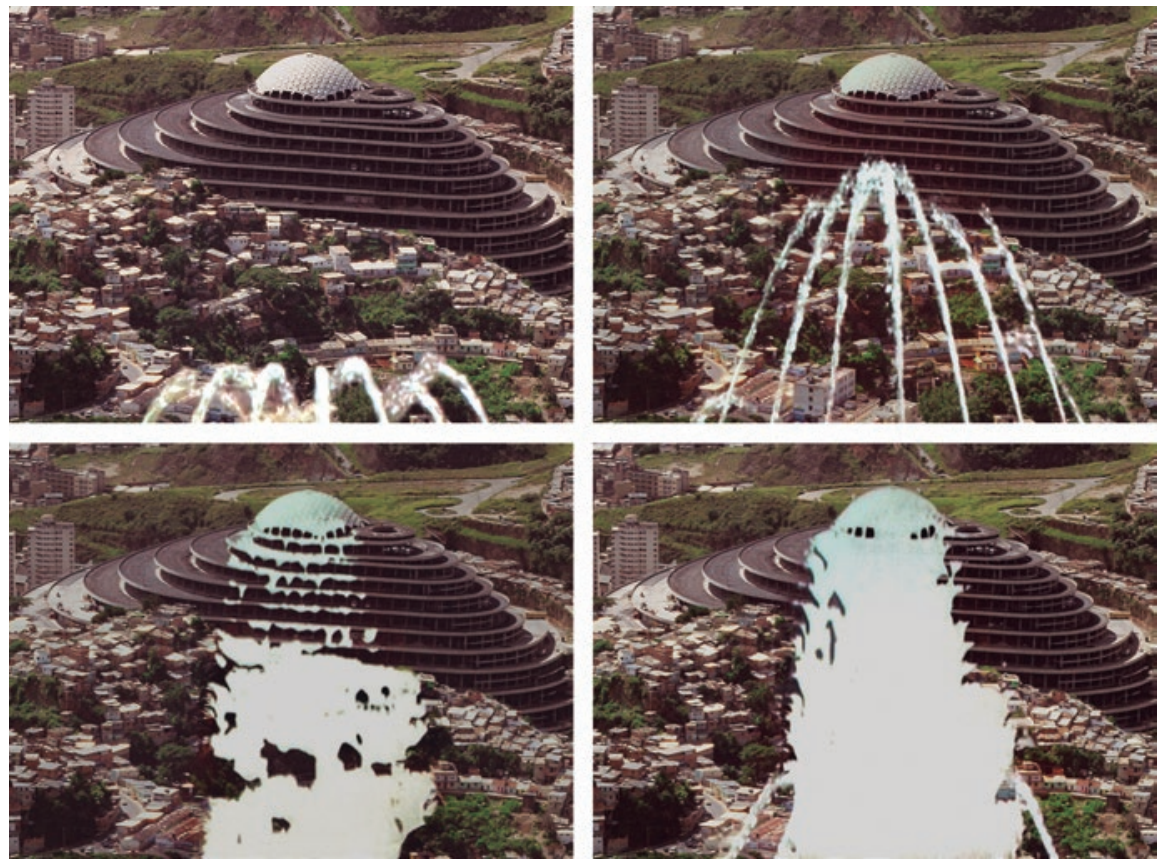

Figura 2. Alexander Apóstol, El Helicoide, de la serie Caracas Suite (2003), 5:30 min.

\section{Restaurar el espectáculo: aguar la fiesta}

Durante los últimos quince años, Alexander Apóstol ha rastreado los nexos existentes entre la arquitectura, la visualidad y la modernidad en Venezuela. Su exposición Caracas Suite (2004) presentó una instalación homónima que indagó el contexto económico, político e ideológico de la modernidad monumental en Venezuela al confrontar la manifestación espectacular de sus hitos urbanos con nuevas escenografías de su arruinamiento. ${ }^{6}$ En Caracas Suite, al son de una pieza de música clásica, cuatro videos simultáneos registran la acción erosiva de

6 Se exhibió en la exposición individual Caracas Suite, en la Sala Mendoza (Caracas, 2004-2005). 
los chorros de una fuente ornamental ubicada fuera del cuadro (figura 2). Estos van borrando imágenes de archivo de lugares icónicos de los años 1940 a 1950 en Caracas. El Silencio enfoca los bloques homónimos de Carlos Raúl Villanueva, celebrados frecuentemente como umbrales de la modernidad urbana, mientras que 23 de Enero muestra los superbloques residenciales, Golden Towers y las torres gemelas del Centro Simón Bolívar, y El Helicoide representa el edificio modernista rodeado de barriadas.

El uso de un solo plano, en lugar de secuencias de imágenes que construirían una noción del espacio tridimensional, resalta el carácter iconográfico de una tipología de monumentalidad moderna, diseñada para forjar la imagen de una "Nueva Venezuela" a mediados del siglo pasado. El proyecto nació en 1955 de la mano de tres jóvenes arquitectos: el diseño de este centro comercial y la exposición de industrias tendría una forma espiral esculpida de la Roca Tarpeya (un duro peñasco en el centro de Caracas todavía sin urbanizarse) y revestida con rampas de cemento. Los visitantes recorrerían sus más de 300 tiendas, sus oficinas y sus clubes sociales, al igual que su hotel, su cine, sus estudios de televisión, sus concesionarios automovilísticos, sus bombas de gasolina y otros servicios, en automóvil o accediendo al complejo por cuatro ascensores (Villota 420). La ruta circular llegaría hasta la cima, en donde la visita culminaría con una exposición de $2300 \mathrm{~m}^{2}$ que sería una vitrina del potencial industrial de Venezuela y promovería sus sectores de petróleo, petroquímica, gas, hierro, aluminio y agricultura.

En su momento, El Helicoide era la síntesis del impulso político de ostentar la modernización que promovía el gobierno militar que se instaló en 1948; un claro signo, además, de la expansión del capital privado, que provenía de la consolidación de la industria del petróleo. ${ }^{7}$ Los años 1950 en

7 A modo de breve contextualización, la muerte del autócrata Juan Vicente Gómez (1908-1935) dio paso a un proceso de democratización que llevó a los primeros sufragios universales en 1946. Salió electo el novelista Rómulo Gallegos en representación de Acción Democrática, pero un sector militar comenzó a inquietarse rápidamente, quejándose de la lentitud del desarrollo nacional. El 24 de noviembre de 1948 una Junta Militar derrocó a Gallegos instalando un gobierno de facto que, para suerte de los militares, coincidió con un alza en los precios petroleros que permitió al Estado invertir sumas masivas en ambiciosos proyectos de obras públicas. Bajo esta inversión, como apunta Castillo (en su estudio de 1990), la "dictablanda" pasó a ser una "dictadura" y también tomó arraigo la forma del moderno petroestado que todavía persiste. Este ente de poderes "mágicos" regula e impulsa el desarrollo nacional por medio de sectores estratégicos y de la centralización de planificación que cambió la vida cotidiana (como sostiene Coronil en su libro de 1997). Otro factor clave de los años 1950 y del contexto de El Helicoide fue la expansión de la cultura petrolera que impactaba la vida urbana y el consumo (ver el texto de Vicente de 2003, y el de Tinker Salas de 2009). 
Venezuela cimentaron el "espectáculo de progreso" en que subyace el modelo de desarrollo del "estado mágico" venezolano, que dispone de las rentas de la industria petrolera para financiar periódicos momentos de intensa mitificación del progreso; lapsos que tienden a materializarse en edificios monumentales que nutren un imaginario consensuado de desarrollo imparable (Coronil 3). Es este espectáculo el que Apóstol re-escenifica en Caracas Suite, y el que dialoga, además, con la instrumentalización de tecnologías visuales, como noticieros, documentales, grandes exposiciones y desfiles, para imbuir en el imaginario colectivo la asociación que puede surgir entre monumentalidad moderna y progreso.

Claramente, en este uso de la monumentalidad como augurio de desarrollo, Venezuela no estaba sola. Ya para 1948, en su aporte al renombrado simposio publicado en Architectural Review sobre la viabilidad de una nueva monumentalidad moderna el urbanista brasilero Lucio Costa había planteado que esta podría instaurar un nuevo orden social. Al redimensionar el entorno humano en sintonía con los avances tecnológicos e industriales, la arquitectura monumental garantizaría "la posibilidad material de sanar, instruir, y educar a las masas", y las "condiciones verdaderamente ideales de vida, transporte, trabajo y ocio" (Paulsson et al. 127). Este presagio utópico sintetizó el impulso desarrollista que imbuyó al largo inventario de construcciones monumentales erigidas en toda la región de América Latina a mediados del siglo xx. Se proponía que la arquitectura moderna lanzaría las naciones directo al futuro, dándoles cincuenta años de progreso en cinco con tan solo implementar una transformación radical del medio físico, para parafrasear los discursos en boga en Brasil y Venezuela en la década de $195^{\circ}$.

En este sentido, las dimensiones monumentales de los edificios que Apóstol muestra aparecen como espectros de esas promesas de una modernización inmediata y total. Al dejar al espectador frente a una pantalla en blanco, la obra revive una corriente intelectual de larga data que sugería que la Nueva Venezuela, forjada con un súbito crecimiento económico, contenía sus propias ruinas en potencia al no ser más que un espejismo. ${ }^{8}$ En De una a otra Venezuela (1945), Uslar advertía que construir una Venezuela fingida con súbita riqueza produciría una nación "tan transitoria como el petróleo con que está construida su apariencia. No más verdadera que una decoración de teatro" (45).

8 Esta corriente ha tenido una fuerte trascendencia en Venezuela a la hora de pensar la cultura urbana y petrolera, como puede apreciarse en los libros de Almandoz, y Martín Frechilla y Texera Arnal (ambas publicaciones del año 2004). 
Apelando a este trasfondo histórico e ideológico, Caracas Suite opera sobre un eje crítico que revive el espectáculo moderno solo para aguar la fiesta. Al movilizar una constelación de referencias, su espectáculo coreografiado interroga el paisaje residual de la monumentalidad hacia dos direcciones simultáneas. Mirando el pasado, las aguas de la fuente ironizan el espíritu triunfante que instrumentalizaba la arquitectura monumental, al presentarla como evidencia del progreso nacional. Observar esta acción desde el presente sugiere más ampliamente que la monumentalidad en sí no es tan sólida, sino que cede fácilmente a la erosión y el arruinamiento. Esta vertebración de la obra capitaliza el potencial de la ruina para actualizarla de un modo productivo, sobre todo porque a pesar de que la fragilidad de las grandes construcciones modernizadoras haya sido más que comprobada, seguimos presenciando cómo a nivel global se presentan monumentales proyectos de intervención topográfica, como represas, minas y fracking, como claves de desarrollo definitivo. Es en este sentido que Caracas Suite ejemplifica el potencial del arte contemporáneo de no limitar la ruina moderna a ser un estímulo de conmemoraciones nostálgicas o melancólicas, sino que apunta a emplearla como una provocación que sitúa la reflexión crítica en los trasfondos ideológicos e implicaciones ecológicas de nuevas pretensiones monumentales.

\section{El Helicoide babélico: tartamudeo del discurso monumental}

Si la obra de Apóstol expone el andamiaje ideológico que sostiene la paridad que existe entre monumentalidad y desarrollo, la instalación La Torre de Babel (1998) de Juan José Olavarría ahonda en el potencial testimonial del monumento arruinado y en su resistencia a significados cohesivos (figura 3). El título de la instalación encuadra el desorden semántico, citando la pintura Torre de Babel de Pieter Bruegel el Viejo (1563), que a su vez glosa el relato bíblico del Génesis que versa sobre la monumentalidad trunca y la comunicación incoherente (Génesis 11.1-9). En este tejido intertextual, El Helicoide luce como un nuevo ícono de ambición monumental cuyo arruinamiento produjo un sinfín de significados y relatos heterogéneos. Lejos de restaurarle algún significado en particular, la instalación apela a la ruina para incitar una revisión histórica al proponer sus mutaciones como una línea de tiempo que traza sucesivos vaivenes sociales, políticos y económicos de la historia reciente en Venezuela. 


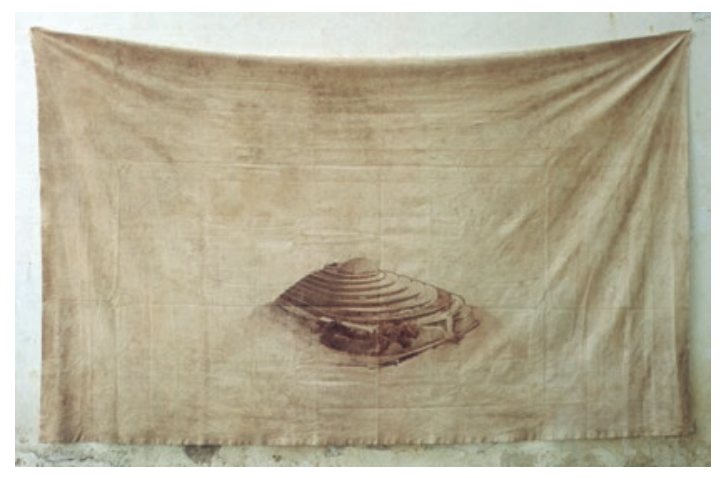

Figura 3. Juan José Olavarría, La Torre de Babel (1998); tinta sobre tela.

Esta productividad de la ruina emerge de la confrontación originada entre las dos piezas que comprenden la instalación. La primera es un dibujo en tinta de El Helicoide en un lienzo rectangular de gran formato, guindado, cual reliquia, de dos grandes clavos oxidados. La segunda es una hoja tamaño carta dispuesta en un sencillo marco de madera que contiene una lista de los más de veinticinco proyectos (incluyendo un ministerio, un cementerio y un museo) propuestos para el edificio en los cuarenta años desde su proyección original, hasta 1998, cuando La Torre de Babel se expuso por primera vez. ${ }^{9}$ A primera vista, la pieza central parece ser el epítome de una representación nostálgica e idealizada de El Helicoide, tanto por sus tonos añejos como por la borradura del entorno urbano que "limpia" el edificio de toda referencia real y lo coloca en el tiempo suspendido de su diseño original. Sin embargo, la borradura del entorno implica un guiño irónico que apunta hacia la conmemoración amnésica o la pretensión de darle un significado definitivo al edificio, al borrar sus usos pasados. De este modo, el tono añejo de la tela es notable ya que también recuerda la superficie vetusta del palimpsesto - justamente un lugar en donde lo visual y lo textual forman un terreno de significados movedizos; en donde múltiples relatos se inscriben, se borran sucesivamente- .

Concebida así, la confrontación de la tela manchada sobre la cual El Helicoide flota sin asidero y la lista de propuestas fallidas, trae a primer plano la idea de que la ruina es un lugar que ofrece resistencia a los relatos teleológicos y, diría Beasley-Murray (en su texto de 2015), a discursos hegemónicos. Ciertamente, los proyectos anotados son pistas que incitan al espectador a interpelar El Helicoide

9 La exposición individual Qué se me quemen las manos de Olavarría tuvo lugar en la Sala Mendoza en Caracas. 
como testigo de la realidad nacional entre los años 1950 y $1998 .{ }^{10}$ Luego de la caída de la dictadura militar en 1958, el edificio cedió a los vaivenes políticos, económicos y hasta meteorológicos de los años subsiguientes. Aunque sería imposible comentarlos todos aquí, un hecho en particular ilumina cómo la materialidad y la información expuesta en La Torre de Babel potencia el rendimiento testimonial y crítico de la ruina. ${ }^{11}$

Como muestra el recuento histórico de la instalación, el Estado propulsó proyecto tras proyecto para el edificio trunco, pero en 1979 le dio uso como refugio para damnificados. A estos habitantes les siguieron otras personas que llegaron al edificio de modo improvisado, generando así una precaria comunidad de unos 9300 residentes que ocupaban las rampas de concreto con barracas y trailers, sin las más mínimas instalaciones sanitarias. Tres años más tarde, según un estudio comisionado por el gobierno local, el lugar se había convertido en un "tumor helicoidal" en la ciudad: un foco de crimen, venta de drogas y prostitución tan preocupante que las autoridades dispusieron desalojarlo, reubicar a los habitantes y luego reinventar El Helicoide como un Museo Nacional de Historia y Antropología.

Este dramático proceso de borradura y reinscripción ha sido el más ambicioso intento de resemantización del lugar. Un equipo de científicos sociales y policías se encargó de su rescate en preparación para "transcendentales misiones futuras" (De Cárdenas 34, 47) como símbolo de progreso que daría una imagen integral de la realidad venezolana. No obstante haber logrado el desalojo y reubicación de los habitantes, la reinvención del edificio no fue tal y en

10 Cabe mencionar que este mismo periodo tiene particular resonancia hoy cuando la historiografía oficial de la Revolución Bolivariana propone un umbral entre la llamada Cuarta República (1958-1998) y la Quinta República, asociada con la presidencia de Hugo Chávez y la Constitución de 1999. Para una discusión del periodo de Chávez ver el texto de López Maya de 2005, y el de Smilde y Hellinger de 2011. La Torre de Babel anticipa el peso de esa periodización, pero es importante notar que no se subscribe a visiones binarias, ni a la recuperación del pasado democrático ni a la ratificación de discursos pro-Chávez que presentan su llegada al poder como un hecho casi inevitable. Lejos de ser tendenciosa, la instalación se centra en visibilizar un turbulento terreno sociopolítico, al hacer memoria de los tantos proyectos propuestos y al hecho consabido de que el edificio permanece como un sitio en contestación.

11 Para un análisis de la transición a la democracia, ver la publicación de Karl del año 1987; y sobre el colapso económico de la década de 1980, ver el estudio de Coronil y Skurski de 1991. Por su parte, en su escrito de 1997 Coronil realiza un análisis invaluable del petroestado moderno, mientras que la Revolución Bolivariana es vista por lentes multidisciplinarios en el estudio de Smilde y Hellinger de 2011. 
poco tiempo El Helicoide cedió a una nueva crisis económica y los disturbios sociales que detonó. En 1983, la deuda externa subió; el precio del petróleo bajó estrepitosamente, y el 18 febrero el bolívar sufrió una devaluación inédita frente al dólar (Coronil y Skurski 293). El proyecto de museo se paralizó y dio paso a la ocupación definitiva del edificio por la Dirección General Sectorial de los Servicios de Inteligencia y Prevención (Disip) en 1985.

Con este contexto en mente, las manchas de la tela de La Torre de Babel no solo evocan un palimpsesto de relatos sino que pueden concebirse como alusiones a la materialidad misma de la ruina, es decir: a los residuos imborrables de los procesos y presencias que atraviesan tales lugares. La reinvención de El Helicoide implicó la limpieza de todo rastro de su ocupación; por tanto, si la tela manchada de la instalación puede estimular una asociación con esos rastros, devuelve algo de ese relato al ámbito de la memoria colectiva y supera el riesgo de que representar la ruina reduzca sus historias a una 'mera' imagen.

En este potencial memorioso de la representación de la ruina se detalla una función afín a la que Jacques Rancière (en su escrito de 2010) confiere a las estéticas disensuales. Estas, propone, van más allá de la producción de significados cohesivos y unificados monumentales, al constituirse como "un elemento sensible desgarrado de lo sensible" (173). Siguiendo estas ideas, la obra de Olavarría se aproxima a un monumento-ruina: un recuento de rastros de proyectos fallidos y presencias borradas de un lugar que resiste a un significado unívoco. Sin embargo, esto no significa que la obra se acople automáticamente a la postura de ciertos críticos que proponen ruinas y escombros (rubble) específicos como señales generales de vías de emancipación futura. En esta vertiente, Beasley-Murray (en su texto de 2015) propone que la ruina per se impulsa un escape poshegemónico, mientras que Gastón Gordillo (en su libro de 2014) cita otra ruina caraqueña, La Torre de David, como evidencia de nuevas subjetividades que resisten sensibilidades elitistas.

Frente a estas promesas abarcadoras, cabe preguntarse si al convocar los discursos truncos del sitio y el tránsito de cuerpos y afectos por El Helicoide, La Torre de Babel no podría interpretarse también como el augurio de una vía emancipatoria. $\mathrm{i} \mathrm{Al}$ representar la ruina como un sitio babélico e incoherente, no apuntaría la obra hacia ese tipo de iluminación? La respuesta sin duda se halla en la lista de proyectos truncos y el destino del edificio. El hecho de que después del fracaso de su conversión en museo el lugar se convirtiera en sede policial lo coloca lejos de las promesas de redención o emancipación y más cerca del aparato represivo del Estado. Hoy, aun habiéndose remodelado 
parcialmente para incorporar la recién creada Universidad Nacional Experimental de la Seguridad (baluarte de la reforma policial), sigue cumpliendo su función como sede policial y carcelaria, cuyas celdas albergan detenidos enmarañados en los conflictos políticos contemporáneos. ${ }^{12}$

Estos hechos imposibilitan el equiparamiento del monumento-ruina de $L a$ Torre de Babel con una narrativa de redención. La obra no incita conmemoraciones nostálgicas, pero tampoco conduce a deducir en sus ruinas el augurio de vías de emancipación, llámense revolucionarias; llámense 'poshegemónicas'. Más bien, esta instalación invita a concebir la ruina como un entramado de relatos y presencias que resiste la cohesión discursiva, pero también recuerda que, a la hora de pensar el potencial de esta ruina en particular, es preciso recordar que el uso policial y carcelario ha sido y sigue siendo su función más duradera, a pesar de los cambios políticos de los años recientes en Venezuela.

\section{Relatar, mirar e imaginar: excavaciones reflexivas}

Uno de los problemas comentados al principio de este artículo fue el riesgo de que las tecnologías de exposición reificaran y aislaran la arquitectura monumental y sus ruinas de sus complejas historias, al privilegiar representaciones "virtuales" que restauran las promesas de sus diseños originales y que silencian los relatos incómodos que van acumulando luego de su emplazamiento. En esta sección final retomaré los hilos de estas cuestiones de las tecnologías de exhibición en sinergia con la discusión de las estrategias curatoriales de una exposición dedicada a El Helicoide, y cómo una instalación particular presentada allí fragua una premisa para ahondar más todavía en el potencial de monumento-ruina comentado arriba.

En 2014 se realizó en Caracas la exposición Helicoides posibles: visiones fantásticas. Organizada por Proyecto Helicoide, una iniciativa creada por

12 La inauguración marcó el intento de asociar El Helicoide con la reforma policial de 2008 y, más ampliamente, con las promesas de renovación nacional pregonadas bajo la Revolución Bolivariana liderada por Hugo Chávez de 1998 hasta su muerte en 2013. Con la creación de la Policía Nacional Bolivariana, que reemplazaría a la Guardia Nacional como ente encargado de dirigir la formación policial, las reformas estaban destinadas a dotar los cuerpos de seguridad de un enfoque humanitario y socialista. En cuanto a la reclusión en El Helicoide y su relación con los conflictos políticos actuales, un caso ilustrativo fue el de Rodolfo González quien, tras ser aprehendido bajo acusaciones de haber coordinado protestas anti-gubernamentales en abril de 2014, se suicidó en su celda en El Helicoide el 13 de marzo de 2015. Su hija ha hablado públicamente de las condiciones de su reclusión, notando el aceso esporádico de luz natural, provisto únicamente por caminatas en los estacionamientos. Ver el texto de Fernández del año 2015. 
la historiadora cultural Celeste Olalquiaga en 2013 para investigar la historia del edificio y generar consciencia colectiva acerca de su valor como artefacto cultural en el paisaje urbano, la muestra marcó una dirección diferente en las prácticas de exposición convencionales, tanto del patrimonio arquitectónico como del arte contemporáneo en Venezuela. ${ }^{13}$ En lugar de separar estas dos esferas, la premisa curatorial de Helicoides posibles las unió en una exposición de dos salas: una trazó la compleja historia del edificio por medio de una cronología ilustrada, mientras que la otra presentó una selección de obras comisionadas para imaginar el edificio en usos alternos a sus funciones actuales (figura 4). Esta aproximación integral puede entenderse como un modo de "excavación" benjaminiana que conjuga distintas temporalidades que rememoran lo que El Helicoide habría de ser, ha sido, y también - por medio de las obras especulativas - lo que pudiera ser. Estas confrontaciones entre el espacio ideal, el "lugar-mundo" y nuevas versiones hipotéticas de El Helicoide, vertebraron una curaduría reflexiva y especulativa que luego influyó en la exposición -Helicoides fallidos: proyectos, ocupaciones y usos de El Helicoide de La Roca Tarpeya (1955-2014) realizada en el Museo de Arquitectura en Caracas ese mismo año-, en donde el diálogo establecido entre pasado y presente se repitió en la ubicación de una maqueta del proyecto original frente a la cronología del edificio. ${ }^{14}$

La incorporación en las exposiciones de fuentes documentales desenterradas durante la investigación —desde bosquejos originales hasta artículos de prensa - junto a las múltiples versiones ficticias del edificio que eran expuestas simultáneamente, demuestra la importancia de este modo de excavación: reflexión esencial a la hora de evitar una "nostalgia restauradora"

13 Desde finales de los años 1990, ocurrió un giro significativo en el campo cultural venezolano hacia la revisión del legado moderno. Por una parte, se registró una producción significativa de artefactos que subrayaron el valor del patrimonio arquitectónico mediante exposiciones, publicaciones de gran formato, documentales e incluso un CD-ROM, formato para ese momento bastante novedoso. Al mismo tiempo, numerosos artistas contemporáneos se volcaron a la estética modernista y sus rastros físicos; entre ellos se destacan Alexander Apóstol, Alessandro Balteo Yazbeck, Mauricio Lupini, Daniel Medina, Juan Nascimiento y Daniela Lovera, entre muchos otros. Estas dos corrientes no tendían a solaparse, con la excepción del trabajo curatorial e investigativo del arquitecto y curador venezolano William Niño Araque, que fusionó una mirada patrimonial con el interés en el arte contemporáneo en un trabajo co-curatorial con Ruth Auerbauch: Torres de Caracas: Modernidad silenciada, que fue expuesto en la Sala Mendoza en el año 2005. En Helicoides posibles colaboraron como co-curadoras Olalquiaga y Fabiola Arroyo. Helicoides fallidos fue curada por Olalquiaga. 
que intentara retornar la ruina a un significado único y coherente (Boym, The Future of Nostalgia 2001). Aun así, este proceso curatorial no implica una negación del valor patrimonial de El Helicoide; al contrario, ambas muestras promovieron un concepto más matizado de patrimonio cultural. Reconocieron el atrevimiento formal de este ejemplo del modernismo arquitectónico al incluir maquetas y memorabilia originales, a la vez que contextualizaron el legado ambivalente del lugar dentro de los hechos ocurridos en los planos político, económico y social. Por ende, en la concepción de El Helicoide como una constelación de significados y funciones cambiantes, las exposiciones se nutrieron de metodologías empleadas en estudios anteriores de Olalquiaga (de los años 1992 y 1998). Como la posmodernidad urbana y lo kitsch, la ruina también se vislumbra como un fenómeno que condensa desencuentros generados por procesos asincrónicos de modernización y urbanización. Aquí, de nuevo, la confluencia de tecnologías de punta del edificio y su actual materialidad degradada, genera un renovado cruce en el seno de la desintegración del aura. Como la misma Olalquiaga ha apuntado: "sólo luego de que el polvo se asienta sobre un objeto comenzamos a añorar su esplendor anterior" ("The Museum of Dust" 34).

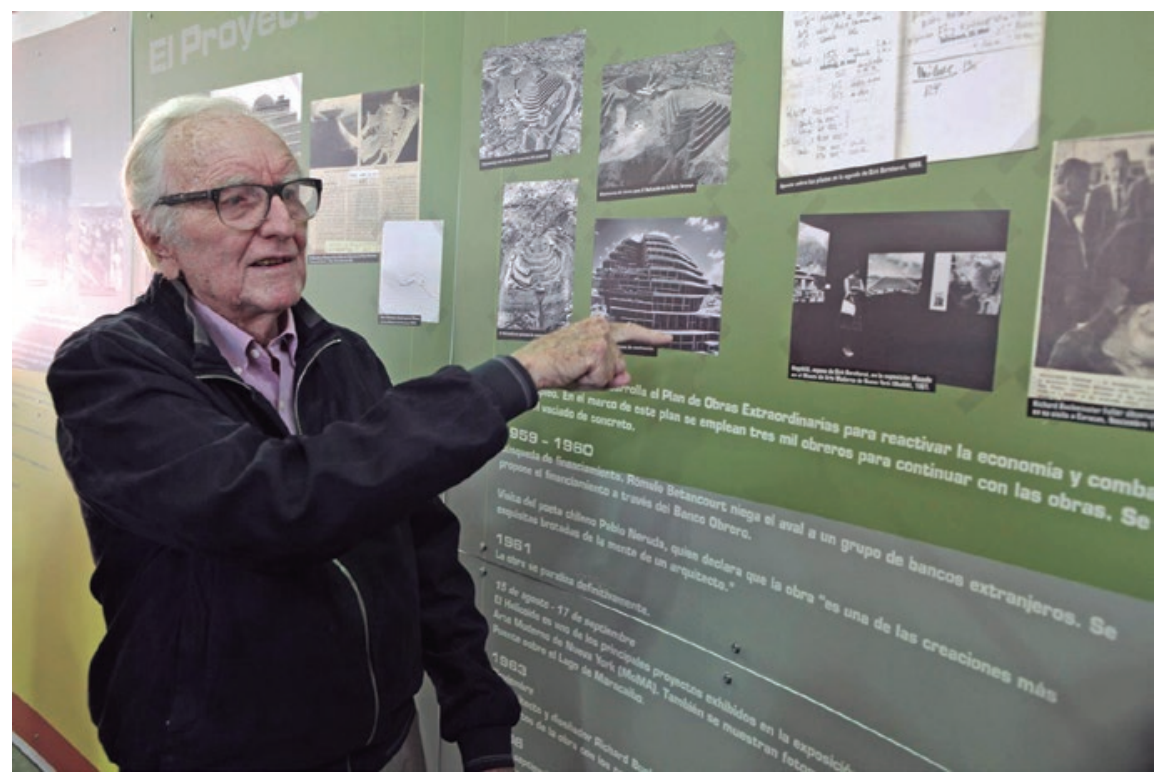

Figura 4. Dirk Bornhorst, uno de los arquitectos originales, revisa la cronología de la exposición Helicoides posibles: Visiones fantásticas (2014). 

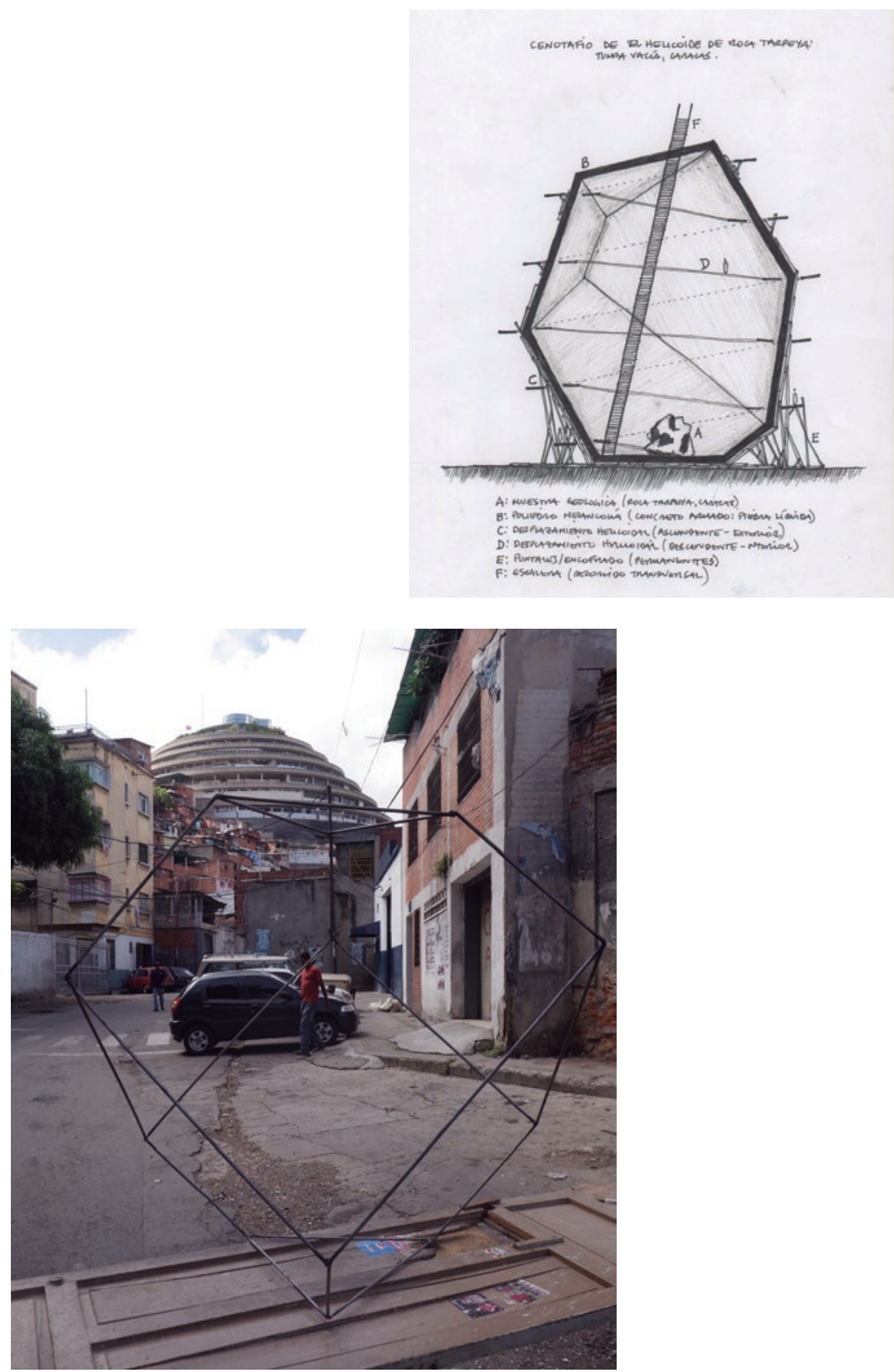

Figuras 5 y 6. Diseño del hipotético monumento; intervención in situ frente a El Helicoide. 


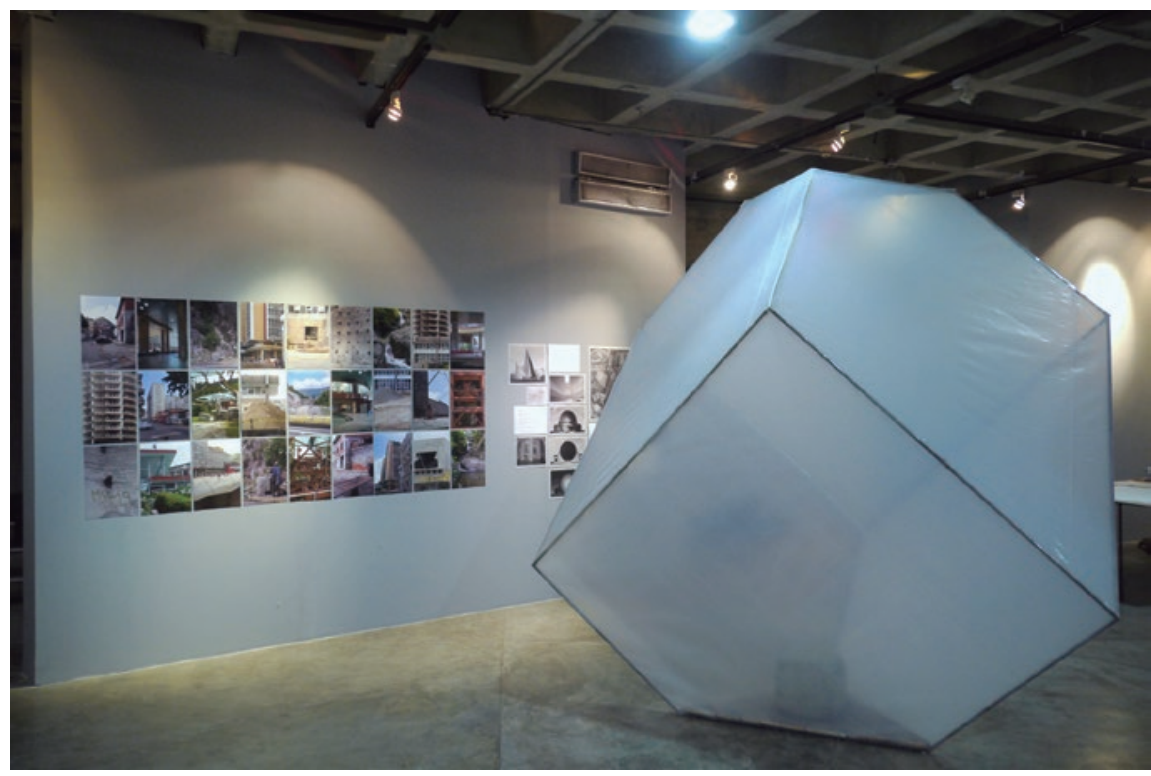

Figura 7. Vista de sala con la obra en maqueta y las imágenes de referencia.

Con más razón, entonces, es necesario indagar en las obras expuestas en Helicoides posibles para ver si ceden a ese impulso nostálgico que Olalquiaga advierte, o si encuentran otras vías para representar la ruina. La premisa especulativa (en lugar de conmemorativa) de las obras comisionadas prefiguró El Helicoide como una zona de contacto entre contexto, cuerpo social y entorno arruinado, a partir de la que los artistas ensayaron nuevos usos para el edificio.

En Melancolía de Roca Tarpeya. Homenaje a la traición (2014) de Federico Ovalles-Ar, Rodrigo Figueroa, Marjiatta Gottopo y Gerardo Rojas, la mirada hacia las ruinas (ruin gaze) se elaboró a partir de prácticas parecidas a la praxis teórico-curatorial. Estas implicaron revisar históricamente el edificio, confrontar su entorno actual y, más significativamente, partir de él para imaginar un paradigma monumental alterno. La instalación consistió en mostrar las distintas fases del diseñar un hipotético espacio monumental que pareció perseguir dos condiciones básicas: primero, interpelar críticamente el diseño de El Helicoide $\mathrm{y}$, segundo, contrarrestar la unidad cohesiva y fija del monumento convencional para ensayar un lugar de "una revelación veloz y transitoria, pero que no le restara su calidad memorable ni monumental" (Huyssen, Present Pasts 46). 
En términos concretos, los materiales expuestos incluyeron polípticos de las referencias textuales y arquitectónicas que informaron la investigación; fotografías de una serie de acciones en las cuales el andamiaje básico para el monumento fue emplazado en diferentes lugares en el paisaje urbano liminal y arruinado de Caracas, y una maqueta a escala dispuesta en la galería. Para el andamiaje del nuevo monumento, los artistas se apropiaron de la forma geométrica del icónico grabado de Albrecht Dürer Melancholia I (1514), que aparece al lado de herramientas abandonadas y un arquitecto frustrado; disposiciones que connotan, así, el fracaso arquitectónico y los proyectos truncos. Reciclado medio siglo después en la ecología de ruinas de Melancolía, el monumento sirvió como un doble de El Helicoide: un "cenotafio" melancólico que sintetiza la productividad del imaginario de las ruinas que Andreas Huyssen identifica como su "consciencia nada nostálgica de la transitoriedad de toda grandeza y poder, la advertencia de presunciones imperiales, y el recuerdo que la naturaleza está presente en toda cultura" ("Authentic Ruins" 54).

Aunque la forma de Dürer se presentó como una tumba que alegorizaba la muerte de la utopía moderna de la cual El Helicoide fue baluarte, este uso del léxico monumental convencional no intentó restaurar el modernismo como un "hogar perdido" de "la verdad y la tradición" (Boym, The Future of Nostalgia 41). $\mathrm{Al}$ contrario, la instalación partió de un vaciamiento de la conexión causal que se da entre monumentalidad y progreso. Además de declararse un "cenotafio" de la modernidad, la figura 5 aclara que Melancolía no contempló un monumento de volumen monolítico, sobre todo porque su propio andamiaje ya venía signado por la advertencia ante la ambición arquitectónica vía la relación intertextual con el grabado de Dürer. Segundo, es significativo que la instalación transparentó lo que Boym, en su texto de 2009, llamaría el "andamiaje filosófico-político" del monumento, al mostrar junto a la maqueta las fuentes de investigación y el proceso de colocar el andamiaje desnudo en espacios urbanos. Finalmente, según el diseño, una vez instalado, el nuevo monumento sería una estructura transitable y permeable. Sus rampas en espiral, sostenidas por soportes visibles, terminarían por eliminar todo rasgo monolítico. Además, el itinerario por el lugar se planteó como una versión espectral del recorrido optimista propuesto en los diseños originales de El Helicoide. Mientras el centro comercial se basó en una trayectoria teleológica que pasaría del consumo drive-through a la gran exposición industrial, en el nuevo monumento el peatón alcanzaría la cima para luego descender al interior cavernoso de la estructura. Allí se encontraría un solo escombro monumental colocado en el piso: un recuerdo de la violencia topográfica ejercida sobre la naturaleza para moldearla en 
las formas que el modernismo inventó para señalar la predominancia del hombre sobre el medio físico. En síntesis, estos múltiples vaciamientos redimensionaron el monumento-ruina como un andamiaje autoreflexivo negado a amoldarse a los paradigmas monumentales que, como Huyssen apunta, hoy generan tantas sospechas, logrando así abordar el reto de "plantear la pregunta sobre la monumentalidad de maneras potencialmente nuevas" (Present Pasts 40).

La última capa en Melancolía que potenció la ruina como fundación para un nuevo tipo de monumentalidad se advierte en la selección de un terreno de construcción a pocos metros de El Helicoide - un lugar en sí vaciado por la reciente demolición de una notoria cárcel urbana-. Esta decisión no fue en absoluto casual. Construida en 1964, la cárcel La Planta se había convertido en años recientes en un ícono del deterioro, los motines violentos y el hacinamiento que caracterizan el sistema penitenciario en Venezuela (como los señala Morais en su estudio de 2009), y de las tasas crecientes de crimen y delincuencia (como demuestran Unodc en su estudio de 2012 y Zubillaga, en el de 2013), que desestabilizan los optimistas relatos de la Revolución Bolivariana y sus promesas de realización y desarrollo a escala nacional. En 2012, ministros del gobierno convocaron una transmisión televisiva en vivo para "inaugurar" la demolición de la cárcel, usando los buldóceres y los escombros como fondo para desvelar sus planes para un vasto parque comunal que sería emplazado en el terreno vaciado (VTV). Esta estrategia comunicacional comprobó la vigencia duradera de un discurso monumental que desplaza lugares problemáticos y propone espacios ideales que renuevan promesas de definitiva realización nacional. En este sentido, al proponer la construcción de su hipotético nuevo monumento sobre los escombros de la cárcel demolida, Melancolía no planteó un nuevo comienzo. Se concibió de antemano como un palimpsesto que incorporaría diversos arruinamientos como los cimientos de una monumentalidad alterna en donde ni la renovación de discursos teleológicos ni la añoranza de grandezas anteriores tendrían lugar.

En resumen, tanto Melancolía como las otras dos obras analizadas aquí confrontan directamente muchos de los interrogantes planteados al comienzo de este artículo. Si uno de estos consistió en preguntar cómo se podría evitar banalizar o romantizar las ruinas modernas a la hora de representarlas, estas tres obras han mostrado que su figuración como imagen no necesariamente equivale al silenciamiento de su capacidad de atestiguar los heterogéneos procesos que condujeron a su arruinamiento. Se identificó un primer paso en formular una mirada contemporánea de las ruinas en el hecho de reconocer que la arquitectura moderna se erigió sobre andamiajes tanto materiales como ideológicos. De ese modo, la obra de Alexander Apóstol mostró la pertinencia de convocar 
nuevamente la paridad entre monumentalidad y progreso, solo para desnudar su discurso triunfante al acelerar el espectáculo del arruinamiento del legado que ese impulso dejó en Caracas.

Por su parte, el contraste que La Torre de Babel genera entre la imagen idealizada de El Helicoide y su proceso de decadencia, reveló su potencial para estimular la revisión histórica, con el propósito de problematizar esquemas arquitectónicos e ideológicos anteriores y confrontar nuevas apuestas críticas que extrapolan ruinas específicas a potenciales emancipaciones generalizadas. Finalmente, al transparentar la concepción de un nuevo monumento que anuncia su propia precariedad e incorpora en sus andamiajes procesos anteriores de arruinamiento, Melancolía de Roca Tarpeya permitió resaltar prácticas estéticas que interrogan los monumentalismos del pasado a la vez que confrontan la tendencia duradera a asociar nuevas construcciones monumentales con promesas de desarrollo definitivo.

En síntesis, frente a los desafíos de dar cuenta del legado moderno y sus ruinas actuales, es evidente que el arte contemporáneo abona un terreno fértil que genera encuentros entre las tecnologías expositivas y visuales, la teoría y la historia culturales. Ofrece vías productivas para reconocer el valor patrimonial de la monumentalidad moderna, pero también para evaluarla como una categoría estética condicionada por la historia y para ver cómo sus ruinas atestiguan desencuentros propios de la modernidad. En este sentido, el aporte que el arte contemporáneo puede hacer a esta tarea crucial no solo consiste en su reflexión sobre el pasado, sino en su creación de contextos para renegociar pactos visuales y espaciales que nos invitan a divisar formas alternas de monumentalidad más acordes con el mundo precario que habitamos.

\section{Obras citadas}

Almandoz, Arturo. La ciudad en el imaginario venezolano II. Caracas:

Fundación para la Cultura Urbana, 2004. Impreso.

Beasley-Murray, Jon. "La utopía en ruinas". Documento proveniente

del I Simposio de la Sección de Estudios del Cono Sur

(LASA), Santiago de Chile, agosto de 2015. Web.

Bornhorst, Dirk. El Helicoide. Caracas: Oscar Todtmann, 2007. Impreso.

Boym, Svetlana. "Ruins of the Avant-garde". Ruins of Modernity. Eds. Julia Hell y

Andreas Schönle. Durham y Londres: Duke University Press, 2009. 58-88. Impreso.

Boym, Svetlana. The Future of Nostalgia. Nueva York: Basic Books, 2001. Impreso.

Cárdenas, Rodolfo. "Prólogo". Proyecto Helicoide. Caracas:

Gobernación del Distrito Federal, 1982. 5-8. Impreso. 
Casey, Edward. The Fate of Place. Berkeley: University of California Press, 2013. Impreso.

Castillo d'Imperio, Ocarina. Los años del buldózer: Ideología y política 1948-1958. Caracas: Ediciones Tropykos, 1990. Impreso.

Coronil, Fernando. The Magical State: Nature, Money and Modernity in Venezuela. Chicago: University of Chicago Press, 1997. Impreso.

Coronil, Fernando y Julie Skursi. "Dismembering and Remembering the Nation: The Semantics of Political Violence in Venezuela". Comparative Studies in Society and History 33.2 (1991): 288-337. Impreso.

De Cárdenas, Sonia. "El problema social". Proyecto Helicoide. Caracas: Gobernación del Distrito Federal, 1982. 25-48. Impreso.

Del Real, Patricio. "Building a Continent: MoMA's Latin American Architecture Since 1945 Exhibition". Fournal of Latin American Cultural Studies 16.1 (2007): 95-110. Impreso.

Dillon, Brian. Ruin Lust. Londres: Tate Britain, 2014. Impreso.

Fernández, Airam. "Habla la hija de 'El Aviador". Contrapunto, 25 de marzo de 2015. Web. 31 de marzo de 2015.

Gallo, Rubén. "Modernist Ruins: The Case Study of Tlatelolco". Telling Ruins in Latin America. Eds. Michael J. Lazzara y Vicky Unruh. Londres: Palgrave Macmillan, 2009. 107-120. Impreso.

Gordillo, Gastón. Rubble: The Afterlives of Destruction. Durham y Londres: Duke University Press, 2014. Impreso.

Hell, Julia y Andreas Schönle, eds. Ruins of Modernity. Durham y Londres: Duke University Press, 2010. Impreso.

Huyssen, Andreas. "Authentic Ruins". Ruins. Ed. Brian Dillon. Cambridge: MIT Press, 2011. 52-54. Impreso.

Huyssen, Andreas. Present Pasts: Urban Palimpsest and the Politics of Memory. Stanford: Stanford University Press, 2003. Impreso.

Jaguaribe, Beatriz. "Modernist Ruins: National Narratives and Architectural Forms". Public Culture 11.1 (1999): 294-312. Impreso.

Karl, Terry Lynn. "Petroleum and Political Pacts: The Transition to Democracy in Venezuela". Latin American Research Review 22.1 (1987): 63-94. Impreso.

Kirshenblatt-Gimblett, Barbara. "Theorizing Heritage". Ethnomusicology 39.3 (otoño 1995): 367-380. Impreso.

Lazarra, Michael y Vicky Unruh. Telling Ruins in Latin America. Londres: Palgrave Macmillan, 2009. Impreso.

López Maya, Margarita. Del viernes negro al referendo revocatorio. Caracas: Alfa, 2005. Impreso. 
Macaulay, Rose. Pleasure of Ruins. Londres: Weidenfeld and Nicholson, 1953. Impreso. Martín Frechilla, Juan José y Yolanda Texera Arnal. Petróleo nuestro y ajeno: La ilusión de la modernidad. Caracas: Universidad Central de Venezuela, 2004. Impreso.

Morais, María Gracia. Situación actual de los derechos humanos en las cárceles en Venezuela. Caracas: Instituto Latinoamericano de Investigaciones Sociales, 2009. Web. 3 de abril de 2016.

Olalquiaga, Celeste. Megalópolis: Contemporary Cultural Sensibilities. Minnessota: University of Minnessota Press, 1992. Impreso.

Olalquiaga, Celeste. The Artificial Kingdom: A Treasury of Kitsch Experience. Nueva York: Pantheon, 1998. Impreso.

Olalquiaga, Celeste. "The Museum of Dust" (2007). Ruins. Ed. Brian Dillon. Cambridge: MIT Press, 2011. 32-5. Impreso.

Olalquiaga, Celeste. "Tropical Babel". Cabinet 52 (invierno 2013-2014): 50-5. Impreso.

Olavarría, Juan José. Qué se me quemen las manos. Catálogo de exposición. Caracas: Sala Mendoza, 1999. Impreso.

Paulsson et al. "In Search of a New Monumentality: A Symposium by Gregor Paulsson [et al.]". Architectural Review 104 (septiembre 1948): 117-28. Impreso.

Rancière, Jacques. "The Monument and Its Confidences". Dissensus: On Politics and Aesthetics. Trad. S. Corcoran. Londres: Bloomsbury, 2010. 169-183. Impreso.

Smilde, David y Daniel Hellinger. Venezuela's Bolivarian Democracy: Participation, Politics, and Culture under Chávez. Durham y Londres: Duke University Press, 2011. Impreso.

Tinker Salas, Miguel. The Enduring Legacy: Oil, Culture, and Society in Venezuela. Durham y Londres: Duke University Press, 2009. Impreso.

United Nations Office on Drugs and Crime (Unodoc). Global Study on Homicide 22 (2013). Web. 3 de abril de 2016.

Uslar Pietri, Arturo. De una a otra Venezuela. $2^{\mathrm{da}}$ ed. Caracas: Monte Ávila Editores, 1985. Impreso.

Venezolana de Televisión (VTV). "Con la demolición de La Planta inicia fase de construcción del Parque Comunal Cipriano Castro". VTV, 1 de septiembre de 2012. Web. 1 de abril de 2016.

Vicente, Henry. "La arquitectura urbana de las corporaciones petroleras: Conformación de 'distritos petroleros' en Caracas durante las décadas de 1940 y 1950." Espacio Abierto 12.3 (2003): 391-414. Impreso.

Villota, Jorge. The Hyper Americans! Modern Architecture in Venezuela during the 1950s. Dis. U. of Texas at Austin, 2014. Impreso.

Zubillaga, Verónica. "Menos desigualdad, más violencia: la paradoja de Caracas". Nueva Sociedad 243 (2013): 104-118. Impreso. 